\title{
FULL-SCALE MEASUREMENTS OF VERTICAL MOTIONS ON ULTRA LARGE CONTAINER VESSELS IN SCHELDT ESTUARY
}

\author{
Jeroen Verwilligen and Katrien Eloot, Flanders Hydraulics Research, Belgium \\ Marc Mansuy and Marc Vantorre, Maritime Technology Division, Ghent University, Belgium
}

\section{SUMMARY}

From September 2017 to July 2018 the Flemish Pilotage executed nine ship measurements on container ships to and from Antwerp. The measurement results were processed by Flanders Hydraulics Research and Ghent University providing 6 DoF motions of the vessels. Furthermore environmental data regarding tide, currents, waves, bathymetry and AIS were processed in order to assess the influence of environmental conditions on the vertical motions of container ships.

The paper presents the vertical ship motions separately for steady and unsteady sinkages in different DoF. As such the relation with ship squat, hydrostatics, sea keeping, turning, steering and ship-to-ship interaction could be assessed and related to the driving parameters such as ship speed, rate of turn, under keel clearance, water density, waves, rudder action and ship meetings.

\section{NOMENCLATURE}

$\begin{array}{ll}\text { B } & \text { Beam }(\mathrm{m}) \\ \mathrm{C}_{\mathrm{B}} & \text { Block Coefficient }(-) \\ \mathrm{GG} & \text { Free Surface Correction }(\mathrm{m}) \\ \mathrm{GM} & \text { Metacentric Height }(\mathrm{m}) \\ \mathrm{L}_{\mathrm{OA}} & \text { Length over All }(\mathrm{m}) \\ \mathrm{L}_{\mathrm{PP}} & \text { Length between Perpendiculars }(\mathrm{m}) \\ \mathrm{s} & \text { Running Distance }(\mathrm{km}) \\ \mathrm{SOG} & \text { Speed over Ground }(\mathrm{kn}) \\ \mathrm{T}_{\mathrm{A}} & \text { Draft at Aft Perpendicular }(\mathrm{m}) \\ \mathrm{T}_{\mathrm{F}} & \text { Draft at Fore Perpendicular }(\mathrm{m}) \\ \mathrm{UKC} & \text { Under Keel Clearance }(\% \text { of draft) }\end{array}$

\section{INTRODUCTION}

\subsection{ACCESSIBILITY PORT OF ANTWERP}

The port of Antwerp is the largest port in the Scheldt estuary. The port is connected to the deep water channels in the North Sea by restricted access channels in coastal waters (sea trajectory of $55 \mathrm{~km}$ or $30 \mathrm{~nm}$, routes $1,2,3,4$, 6 and 7 in Figure 1) and on the river Scheldt (river trajectory of $70 \mathrm{~km}$ or $38 \mathrm{~nm}$, route 8 and 9 in Figure 1).
The restricted depth of the access channels on the sea- and river trajectory, combined with an important tidal range of 4 to $6 \mathrm{~m}$, results in tidal restrictions for the accessibility for deep-drafted vessels. The Common Nautical Authority (CNA) provides the tidal windows during which vessels are allowed to sail inbound or outbound.

At present the CNA evaluates the accessibility of the port of Antwerp based on a deterministic method considering a minimum value for the gross under keel clearance (vertical distance between the water depth and the static draft), expressed either in metre or as a percentage of the ship's draft. This accepted keel clearance criterion depends on the channel and the ship type, taking account of the local wave climate and the ships' speed range. For ships in arrival to or departure from the port of Antwerp, the following limitations are currently applied in the approach channels (see Figure 1):

- $15.0 \%$ of draft at the sea trajectory (routes 1,2 , $3,4,6,7)$

- $12.5 \%$ of draft for the Western Scheldt (route 8);

- $10.0 \%$ of draft for the Lower Sea Scheldt (route 9).

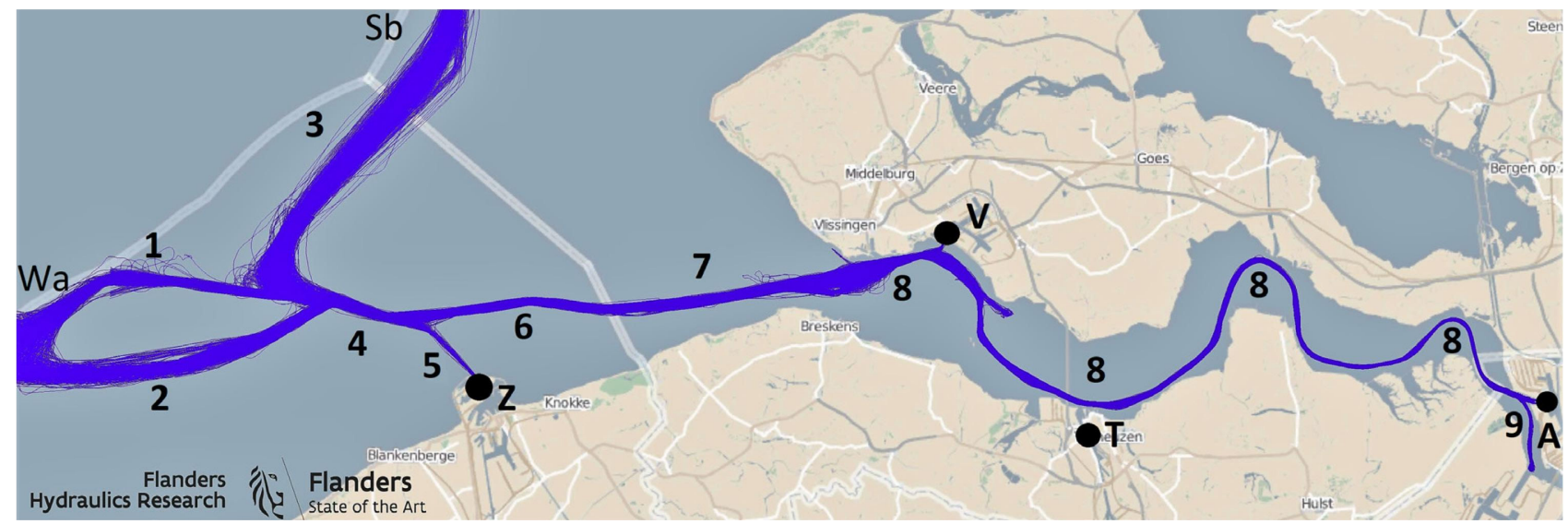

Figure 1. Access channels and harbours in the Scheldt estuary. 1: VG1, 2: A1, 3: West Rond, 4: Scheur West, 5: Pas van het Zand, 6: Scheur East, 7: Wielingen, 8: Western Scheldt, 9: Lower Sea Scheldt. A: Antwerp/Antwerpen (B), T: Terneuzen (NL), V: Flushing/Vlissingen (NL), Z: Zeebrugge (B), Wa: Wandelaar, Sb: Steenbank. 
In order to optimize the accessibility for deep-drafted vessels, the CNA is evaluating the application of a probabilistic access policy based on criteria related to bottom touch and manoeuvring margin. In a probabilistic approach a prediction tool for vertical ship motions is the basis for defining minimal under keel clearances (Vantorre et al., 2014).

\section{$1.2 \quad$ FULL-SCALE MEASUREMENTS}

Since 2014, the CNA is initiating projects to collect actual data regarding the vertical ship motions in the access channels to the ports along the river Scheldt. In 2015 the CNA ordered a measurement campaign on cape size bulk carriers with a draft of $16.5 \mathrm{~m}$, sailing inbound to the port of Flushing/Vlissingen (NL), part of North Sea Port (Verwilligen et al., 2018a and Verwilligen et al., 2018b). In 2017 a similar project was initiated for deep drafted container vessels sailing to or from the port of Antwerp. In both cases the measurements were performed by the pilotage (Dutch and Flemish Pilotage, respectively) while processing and analysis were performed by Flanders Hydraulics Research (FHR) and Ghent University, Maritime Technology Division (UGent).

This paper will present the vertical ship motions for nine container vessels sailing outbound (8) from or inbound (1) to the port of Antwerp.

\subsection{VERTICAL SHIP MOTIONS}

In order to relate the vertical motions to different causes, the motions are split into steady (low frequency) and unsteady (high frequency) motions. Steady motions can be related to slowly varying parameters such as ship speed; rate of turn; under keel clearance and blockage; tidal level and currents; salinity of water; overtaking manoeuvres; constant rudder angles and wind. Unsteady motions on the other hand can be the result of phenomena like: ship response to waves (seakeeping); ship meetings (encounters); rudder deviations and wind gusts.

\section{SHIP MEASUREMENTS}

\section{$2.1 \quad$ SHIPS AND VOYAGES}

From September 2017 to July 2018 the Flemish Pilotage executed nine full-scale measurements on container ships, designated as ULCS $1-9$, to and from Antwerp. Figure 2 and Table 1 present the shipping trajectories and the main particulars of the ships and voyages, respectively.

It can be observed that the first eight measurements corresponded to outbound trajectories. The focus on outbound measurements is resulting from different reasons, such as the shorter tidal windows (and most likely occurrence of small UKCs), the (in general) larger drafts and the favourable conditions to set up the measurement equipment when the vessel was moored. For the eight outbound container vessels, seven were sailing to the Western pilot station Wandelaar, while the vessel ULCS 5 was sailing to the Northern pilot station Steenbank. The Northern trajectory included an important turning manoeuvre at sea. For the vessel sailing to the Wandelaar, only ULCS 6 applied the fairway via A1, while the others applied the fairway via VG1 (see Figure 1). The last measurement concerned an inbound voyage. ULCS 9 was also coming from the Northern pilot station Steenbank.

Based on the horizontal dimensions the vessels can be divided into two groups. Six out of nine vessels had a length close to $366 \mathrm{~m}$ and a beam close to $51.2 \mathrm{~m}$. The mean draft of those vessels (all outbound) varied between $11.3 \mathrm{~m}$ and $14.8 \mathrm{~m}$. The three other container vessels all had a length superior to $397 \mathrm{~m}$ and a beam larger than $56 \mathrm{~m}$. The mean draft of the three largest container vessels varied between $10.1 \mathrm{~m}$ for the inbound vessel and $15.1 \mathrm{~m}$ for one of the outbound vessels.

For the first seven voyages the crew performed a water density measurement when the vessel was at the quay. presents these densities with the corresponding hydrostatic position of the ship. For the last two voyages no density measurements were provided. For these vessels the drafts are presented for fresh water conditions $\left(1000 \mathrm{~kg} / \mathrm{m}^{3}\right)$.

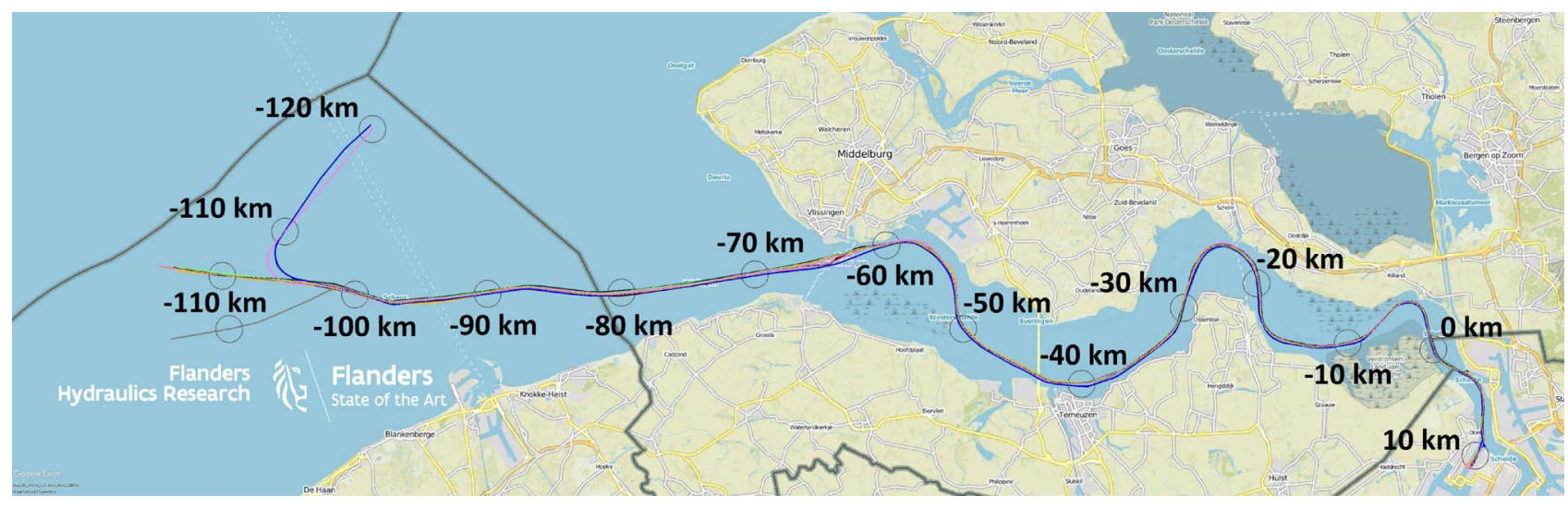

Figure 2. Trajectories for nine container vessels with running distances (colour code see Table 1) 
Table 1. Main particulars of nine container vessels measured

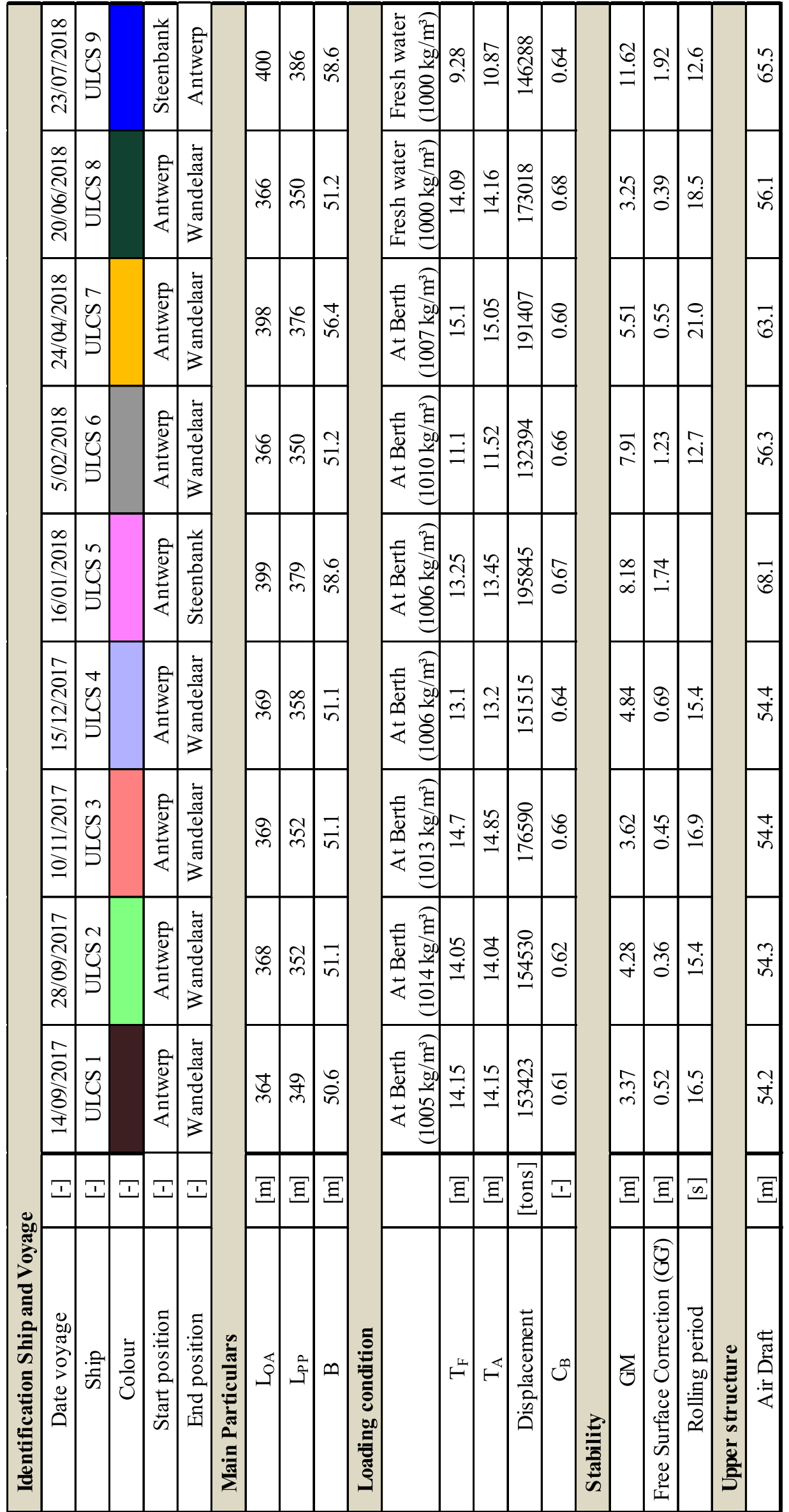




\subsection{MEASUREMENT EQUIPMENT}

During the full-scale measurements to and from the port of Antwerp, dedicated measurement equipment was installed to monitor:

- $\quad$ ship positioning in $6 \mathrm{DoF}$;

- the application of rudder and propeller.

An important requirement for the measurement system was related to the installation and set up on board: two pilots should spend no more than 45 minutes to set up the measuring equipment and to start the measurements.

\section{2 (a) Positioning equipment}

\section{Full SNMS (ADX)}

Similar to the measurements performed on the cape-size bulk carriers to Flushing/Vlissingen (Verwilligen et al., 2018a), the measurement equipment used on container vessels was based on the Full SNMS positioning system (van Buuren, 2005). The Full SNMS positioning system provides both Dutch and Flemish Pilotage with accurate positioning of marginal ships referred to an electronic chart with highly accurate and recent information on bathymetry, aids to navigation and nautical infrastructure. In the SNMS-application, the position of the ship's contour is based on a horizontal position and a heading defined for a reference point. In case of a Full SNMS the horizontal positioning is based on the positioning information from two RTK-GPS antennas that come with the SNMS equipment. The positioning system related to the Full SNMS is also referred to as the AD Navigation ADX-Series (short: ADX). The Full SNMS pilot will install the ADX-antennas on a suitable ship position (e.g. the bridge wings) and relates the position of the antennas to the ship contour by measuring the longitudinal (to bow) and lateral (to starboard side) distance for each antenna. The ADX provides periodic updates of the ship's positioning $(5 \mathrm{~Hz})$ with high accuracy $(2 \mathrm{~cm})$. However, the quality of the ADX positioning depends on the online availability of RTK-corrections. This external input is provided through a dual sim GPRS-modem, so that accurate positioning is only available in case of a stable data connection to the RTK-server. This results in missing positioning data (gaps) during the measurements.

The Full SNMS application is developed to assist ship manoeuvring and focusses on the representation of the horizontal positioning. As such the software is optimized to provide accurate information on the longitude, latitude and heading of the vessel, corresponding to the three horizontal degrees of freedom: surge, sway and yaw. Furthermore, when the RTK-GPS antennas are installed laterally then the altitude (height) measurement of the antennas can be applied to provide the heave motion and the roll motion of the vessel as well. As a result the standard application of the ADX provides measurements for five out of six degrees of freedom. In order to perform ship position measurements in six degrees of freedom, additional measurement equipment is required to provide pitch information of the vessel.

For measurements on cape-size bulk carriers the pitch motion was obtained by installing a third RTK-GPS antenna on the bow of the ship (Verwilligen et al., 2018a). Unfortunately for container vessels no convenient positions are available to install a third RTK-GPS at bow or stern so that another measurement device was required to measure the pitch motion of container ships.

\section{Octans 4}

In order to allow accurate measurements of the pitch motion of the container vessels, the Dutch ministry of infrastructure and water management (Rijkswaterstaat), provided the Octans 4 measurement device. The Octans combines a gyrocompass (three axis) and motion sensor. According to the manufacturer a standalone application of the Octans 4 provides orientations (roll, pitch and heading) at a RMS-accuracy of 0.01 degree. This accuracy is agreed to be acceptable for the pitch measurement on container ships. The Octans 4 provides motion measurements at $25 \mathrm{~Hz}$ frequency.

\section{2 (b) Installation and setup}

For the application of ADX antennas and Octans on board of container vessels the following configuration was applied (see Figure 3):

- ADX antennas POS and HDG1 installed laterally at a wide distance (e.g. at both bridge wings);

- Octans 4 installed midships on the ship bridge and orientated (exactly) towards the bow.

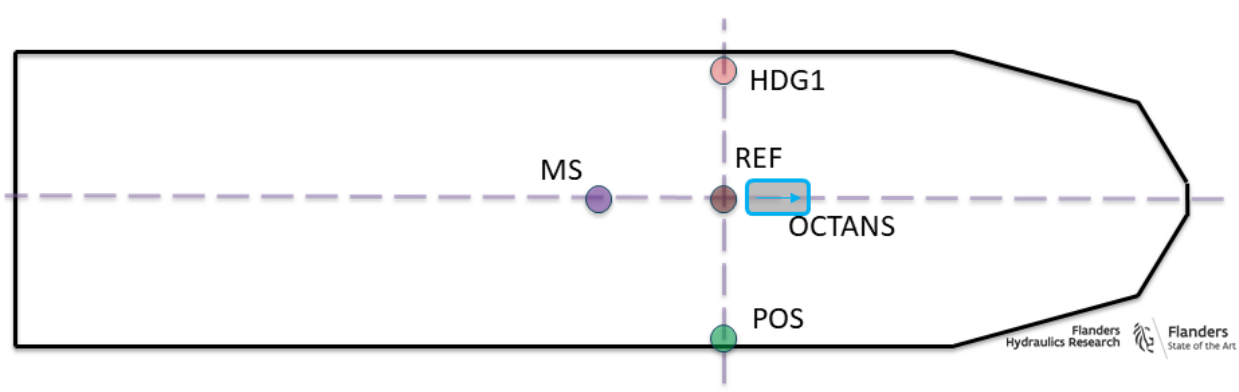

Figure 3. Positions of measuring setup applied on container vessels 


\section{2 (c) Camera monitoring}

In order to monitor the evolution of indicators on the ship bridge, FHR developed a portable camera setup (Geerts et al., 2016). The camera setup consists of three independent camera units that allow to log images at a predefined frequency. The camera units have a magnetic housing, allowing to install them fast and easy on the ceiling of the ship bridge (see Figure 4). For all measurements performed on container vessels, the cameras were installed by the Flemish Pilotage to monitor the rudder indicator, the propeller indicator and the wind indicator at a frequency of $1 \mathrm{~Hz}$.

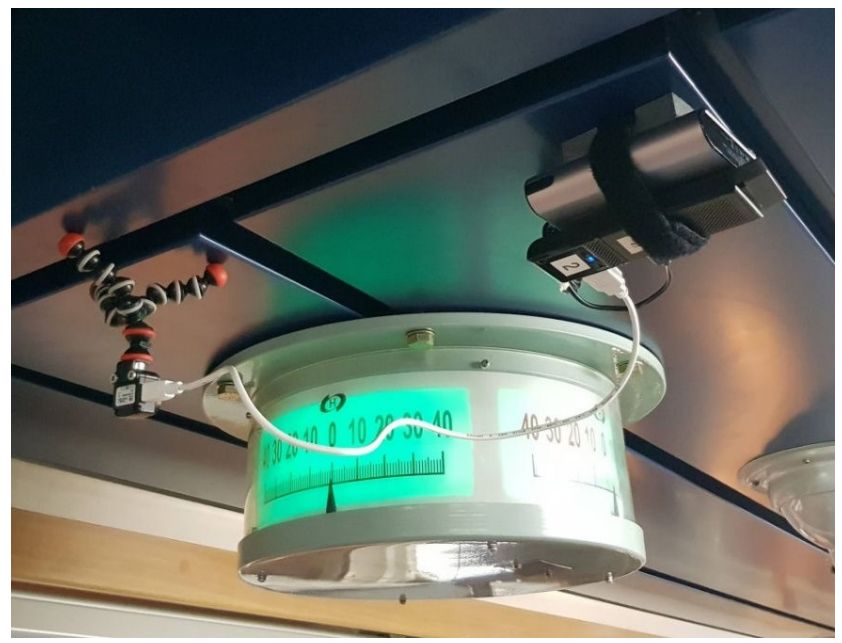

Figure 4. Application of one camera unit on board of an ULCS

\section{DATA PROCESSING}

\subsection{POSITIONING IN 6 DOF}

From the raw measuring data provided by the pilotage, the ship's positions in $6 \mathrm{DoF}$ were processed.

At first, the absolute position of the reference point (REF) is calculated from the ADX-positioning. The reference point is defined as a point in the centreplane of the vessel at the same longitudinal position as the ADX-antennas (see Figure 3). The heading of the vessel is also calculated based on the positions of the ADX-antennas. The roll and pitch angles at the reference point are provided by the Octans 4 measurement. As such the absolute positions of the reference point are defined in six degrees of freedom. By applying the corresponding lever arms, the motions of the vessel's midship (MS) could be calculated.

\subsection{REFERENCE TRAJECTORY}

In order to allow a geographical analysis on the data, the horizontal ship positions (MS) were related to the running distance $(\mathrm{km})$ with respect to a reference trajectory. As a basis for the reference trajectory a mid-fairway curve was applied.

The origin of the reference trajectory was defined at passage point $\mathrm{CP}$ (Coordination Point) closely corresponding to the Dutch-Belgian Border. Positive running distances correspond to positions upstream $\mathrm{CP}$ and negative running distances correspond to positions downstream CP. Figure 2 presents the running distances for the different trajectories applied.

The following areas can be distinguished:

- Port trajectory $(0 \mathrm{~km}<\mathrm{s})$ : vessels are sailing at relatively low speed and waves are absent

- Scheldt trajectory $(-65 \mathrm{~km}<\mathrm{s}<0 \mathrm{~km})$ : vessels are sailing at moderate speed and waves are absent

- Sea trajectory $(\mathrm{s}<-65 \mathrm{~km})$ : vessels are sailing at relatively high speed and important sea states may occur.

\subsection{FALL-BACK FUNCTIONALITY}

The weakest point in the ship monitoring corresponds to dependency of the ADX to RTK-corrections provided through a GPRS-modem. Drop outs of the RTKcorrections results in (sometimes long) unavailability of $\mathrm{ADX}$-measurements. When $\mathrm{ADX}$ measurements are absent, no information on ship positioning is available, so that no geographical processing (on bathymetry and hydro-meteo data) can be performed. Also information on ship speed is missing in case ADX is not working properly.

In case both $\mathrm{ADX}$ and Octans were not measuring (e.g. in case of a crash or reboot of the equipment) then also information on heading and rate of turn was missing.

For abovementioned reasons the positioning data coming from AIS were used in case that the measuring devices were not working properly. AIS-information was obtained from the Scheldt Radar Chain (SRK). It was observed that on condition that the antenna-offsets in the AIS-data were correctly defined, the AIS data were a good alternative for the horizontal ADX positioning. For six out of nine vessels the antenna-offsets were correctly defined in the AIS-data, resulting in a (mean) deviation to the ADXmeasurement smaller than $2 \mathrm{~m}$. For the three other vessels the lateral offset in the AIS-data presented larger deviations to the ADX-measurement (up to $28 \mathrm{~m}$ ). For these vessels a manual update of the AIS information was performed.

The AIS-data (combined with the optimized antenna offsets based on $\mathrm{ADX}$ ) were processed into the following parameters allowing to be applied as a fall-back for the corresponding motion measurements obtained with ADX and Octans:

- latitude MS;

- longitude MS;

- heading;

- $\quad$ ship speed over ground;

- rate of turn. 


\subsection{RELATIVE VERTICAL POSITIONS TO THE WATER LEVEL}

In the project it is the objective to study the evolution of the vertical ship motions for a sailing vessel. This means the vertical motions should be related to the hydrostatic vertical position for the vessel at the quay (in Antwerp):

- rolling and pitching angle are referred to their static and undisturbed value;

- heave motions are related to the water level and referred to a static condition.

\section{4 (a) Static trim and heel}

For each measurement a timeslot of approximately 5 minutes was selected (when possible) for which the vessel was operating in static and free conditions. This static measurement was performed in proximity of the quay because on this location the ship speed was negligible. The following conditions need to be satisfied when defining the static measurement:

- negligible ship speed or rate of turn;

- high quality of ADX positioning;

- the vessel is sailing free and undisturbed (no mooring lines attached, no contact with quay fendering, limited tug action).

The mean roll and pitch angles during the static measurement are defined as the static roll and static pitch and were subtracted from the raw roll and pitch angles measured along the full trajectory.

For some measurements the static conditions defined above could not be met. In that case some uncertainty remains on the absolute value of the roll angle during the measurement.

Throughout this document roll and pitch are defined as the motions corrected with a static offset as described above.

\section{4 (b) Heave referred to water level}

The measurements provides ship positioning with respect to an earth bound coordinate system. In order to assess the sinkage of a vessel, the ship positions should be referred to the instantaneous water plane (see Figure 5).

To achieve this the altitude measurements with respect to the GRS80 ellipsoid were converted to a geodetic reference level (NAP). Then the hydrostatic vertical distance between the antennas and the water surface $\left(\Delta Z_{\text {Static }}\right)$ was deduced from a static measurement (at negligible ship speed). Once the hydrostatic position of the antennas is known, the sinkage of the antenna can be obtained by subtracting the vertical distance between the antenna and the actual waterline $\left(Z_{\text {Tide }}-Z_{\text {Antenna }}\right)$ from the static vertical distance $\left(\Delta Z_{\text {Static }}\right)$.
In a tidal environment, the accuracy of the sinkage measurement depends on (Verwilligen et al., 2018a):

- the accuracy of the altitude measurement by the RTK-antennas $(0.03 \mathrm{~m})$;

- the accuracy of the conversion method to a geodetic reference level $(0.02 \mathrm{~m})$;

- the accuracy of the pitch measurement (0.01 deg);

- the longitudinal distance of the antennas with respect to bow and stern of the vessel;

- the accuracy by which the water level along the trajectory could be reproduced $(0.05 \mathrm{~m}$ on the river trajectory).

As such, when assuming the vessel to be a rigid body the accuracy of the squat was between $0.12 \mathrm{~m}$ and $0.14 \mathrm{~m}$ at the bow and between $0.13 \mathrm{~m}$ and $0.15 \mathrm{~m}$ at the stern.

The vessel is referred to its hydrostatic position so that hydrostatic hogging or sagging of the vessels was taken into account. Nevertheless the measurements do not account for the effect of dynamic hogging and sagging during the voyage (e.g. longitudinal bending due to sea keeping).

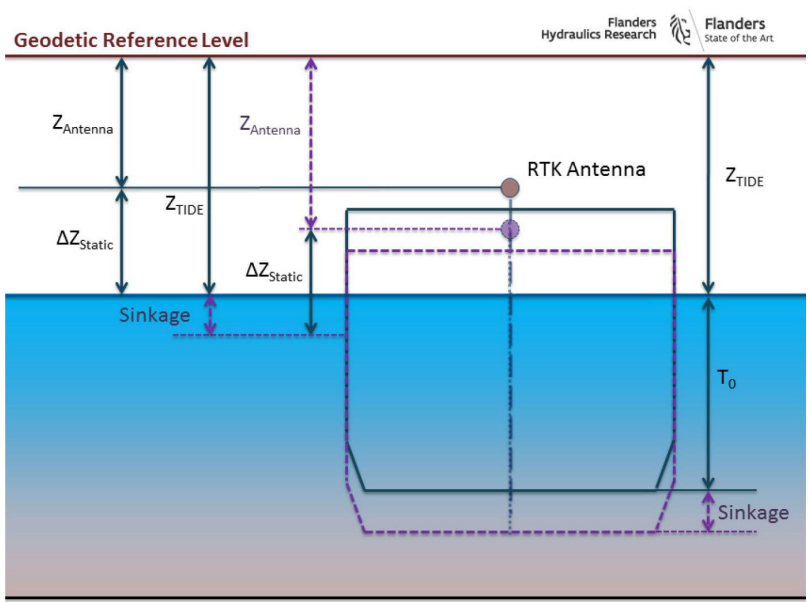

Figure 5. Calculating sinkage in case of constant draft. Full line: static condition; dashed line: sailing condition (Verwilligen et al., 2018a).

\subsection{STEADY AND UNSTEADY MOTIONS}

In order to perform a first analysis on the cause of vertical ship motions, the motions are separated in a steady part and an unsteady part. The steady motions were defined as the 60 seconds running average $([t-30 \mathrm{~s} ; \mathrm{t}+30 \mathrm{~s}])$ of the full motion. The unsteady motions were obtained by subtracting the steady motions of the full motion. As a result the sum of the steady and unsteady motions equals the full motion of the vessel. 


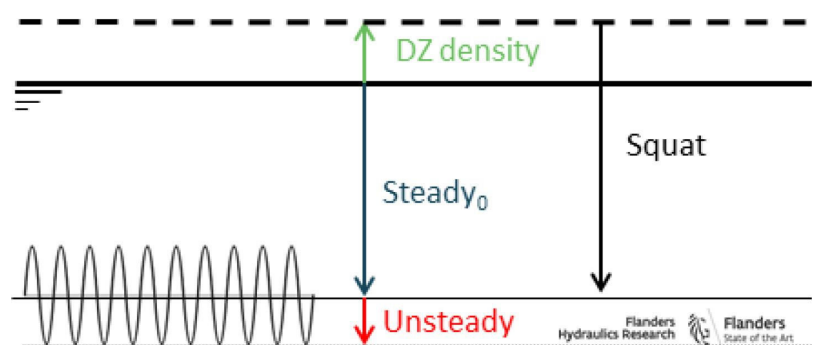

Figure 6. Heave motion components corresponding to unsteady (red), steady (blue) and static (green) motion

\section{5 (a) Heave and pitch}

Figure 6 visualizes the determining phenomena that cause the heave motion of the vessel. From the measurements, the steady and unsteady heave motions are retrieved. The unsteady part of the heave motion corresponds to the response of the vessel to waves or other dynamic external forces. The steady part of the heave motion corresponds to a hydrostatic effect due to density changes and a downwards motion due to squat. In order to investigate ship's squat the steady sinkages provided from the processing in $\$ 3.4$ (b) should be corrected to the varying hydrostatics (draft fore and aft) corresponding to density changes. For vessels sailing outbound, the density effect will have an upward effect on the ship's vertical position (negative sinkage). In case of low ship speeds (and consequently small squat) at a downstream position, this may result in a negative value of the steady sinkage (see $\S 5.1$ ).

In this respect, the pitch motion of the vessel is similar to the heave motion with unsteady motions related to waves and dynamic phenomena and steady motions related to squat and density variations.

\section{5 (b) Roll}

For roll motions the distinction between steady and unsteady motions is less straightforward. The reason is that many parameters can influence the roll motion of the vessels, such as the following parameters that can be considered steady:

- $\quad$ ship speed and rate of turn influencing heeling in bends;

- $\quad$ ship encounters (overtaking);

- constant rudder angles;

- $\quad$ steady wind components.

and the following phenomena related to unsteady motions:

- $\quad$ ship response to waves (seakeeping);

- $\quad$ ship encounters (meetings);

- rudder deviations;

- wind gusts.
Furthermore the unsteady roll motion is strongly influenced by the dynamic rolling behaviour of the vessel, depending on the stability (GM), the rotational inertia and the roll damping of the vessel.

\section{CONDITIONS}

In this chapter the operational and environmental conditions during the nine voyages are presented. Chapter 7 provides a graphical presentation of the measurement results. In those figures the results are referred to the running distance (see \$3.2) presented on the horizontal axis. The running distances are presented with decreasing values so that for outbound voyages, time is increasing from left to right. For the inbound voyage of ULCS 9, the start of the measurement corresponds to the right side of the figure.

\subsection{TIDE AND CURRENT}

In order to reproduce the tide along the trajectory with good accuracy, the results of hindcast simulations performed with the numerical model ZUNOv4 (Dutch ministry of infrastructure and water management, Rijkswaterstaat) were combined with tide measurements available at several stations along the trajectory (see Figure 7). The numerical model provides both tidal levels and 2D current vectors for the full study area with an update period of 30 minutes. From the tide measurements at specific positions, an additional geographically and time varying correction factor for the ZUNOv4 grids was deduced.

Due to lack of measurement data, no optimisation could be performed on the current vectors derived from the ZUNOv4 output. The ZUNOv4 is a two-dimensional model, so that the provided current vectors can be assumed to be depth averaged.

Figure 8 presents the evolution of the water level for the nine container vessels measured. Vessels with a tide dependent draft are presented in a full line and tide independent vessels are presented in a dotted line

It can be observed that despite the small draft of the (only) inbound vessel (ULCS 9), the vessel was following the flood current, leading to rather high water levels along the trajectory.

For the outbound vessels it can be observed that four out of eight outbound vessels (ULCS 2, ULCS 3, ULCS 7 and ULCS 8) did optimise their voyage around high tide. Those vessels depart from the port of Antwerp in flood conditions and reach high tide at a position between $40 \mathrm{~km}$ (Terneuzen) and $-50 \mathrm{~km}$ (Pas van Borssele). These trajectories are typical for tide dependent vessels. The four vessels mentioned all had a draft of more than $14.0 \mathrm{~m}$ which is more than the tide independent draft on the Scheldt (13.1 m). 


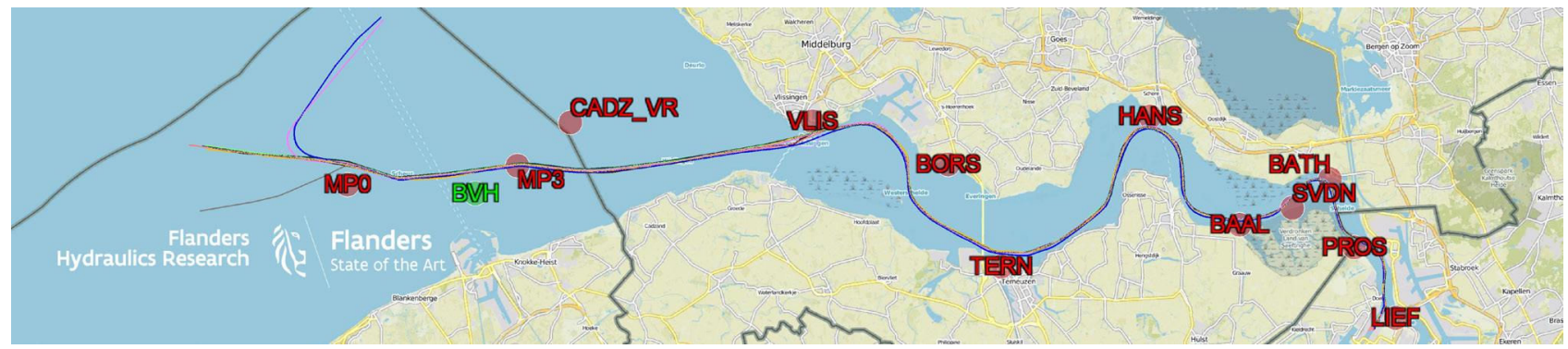

Figure 7. Location of tide (red) and wave (green) measurement stations applied

Three of the other outbound vessels (ULCS 4, ULCS 5 and ULCS 6) were, at some point of the trajectory, sailing at low tide. Those vessels however did have a significantly lower draft, so that on most of the days these vessels will be tide independent. Finally, the vessel ULCS 1 did have a draft of $14.15 \mathrm{~m}$ making the vessel tide dependent (especially on the Western Scheldt).

It can be observed that this vessel was sailing at the end of its tidal window resulting in relatively low tides at the sea trajectory.

The current conditions highly depend on the tidal conditions. In Figure 9 the magnitude of the current vector is presented for the nine measurements. On the sea trajectory $(\mathrm{s}<-65 \mathrm{~km})$ the current is changing gradually while on the Western Scheldt more geographical variations in current speed can be observed. These variations are related to the varying topology of the fairway (e.g. in bends and straight sections). It can be observed that for two vessels (ULCS 6 and ULCS 8) rather large flood currents, with a magnitude of more than $3 \mathrm{kn}$, were experienced.

It should be noticed that the current speeds retrieved from the ZUNO v4 model are depth averaged, while the vessel is only present in the top layers of the water. In general the tide the current is stronger in the top layers of the water then over the complete water column. Some uncertainty remains on the actual current speed (and as a consequence also on the speed through water) experienced by the vessel.

\subsection{BATHYMETRY}

The bottom profile present during the measurements was retrieved from the most recent survey data available at the time of the measurement. For this purpose historical soundings from the Scheldt ECS database (Flemish Hydrography and Rijkswaterstaat) were applied. The survey data were projected on the trajectory followed by the midship (MS), fore perpendicular (FP) and aft perpendicular (AP) of the vessel. The water depth is obtained by summing the tide to the bottom depth.

In Figure 10 the water depth experienced by the nine vessels is presented. It can be observed that especially on the river Scheldt $(\mathrm{s}>-65 \mathrm{~km})$, there is an important geographical variation in depth conditions related to the morphology of the river. For example the river bends correspond to deeper water than the straight stretches. Also the influence of tidal conditions can be observed. For example at running distance $-10 \mathrm{~km}$ (Baalhoek) relatively small water depths were experienced by the vessels ULCS 4 and ULCS 6 . Because of their small drafts, these vessels were tide independent and could pass Baalhoek at low tide conditions.

Figure 11 shows the gross under keel clearance experienced by the vessels. The gross under keel clearance is presented as a percentage of the hydrostatic draft of the vessel at the berth or in fresh water (see Table 1)

) and corresponds to the deterministic definition of the under keel clearance. This figure shows that the smallest under keel clearances occurred in the port trajectory ( $\mathrm{s}>0$ $\mathrm{km}$ ), i.e. at upstream locations close to the port of Antwerp (at the entrance of the Deurganckdok ( $\mathrm{s}=9 \mathrm{~km}$ ) and at the shallow patch of Frederik $(\mathrm{s}=7 \mathrm{~km}))$. For all measurements the under keel clearances at Scheldt and sea trajectory were larger than $20 \%$.

It should be noticed that the minimum under keel clearance available during the measurements is significantly larger than the minimum keel clearance that is prescribed in the actual deterministic calculation $(12.5 \%$ on the river trajectory and $15 \%$ at sea). Actually, the required under keel clearance percentages will eventually be overruled when a probabilistic approach policy will be implemented. The gross under keel clearance should be sufficient to reduce the probability of bottom touch to an acceptably low value, but also the remaining manoeuvring margin, i.e. the average vertical distance between the ship's keel and the bottom during the transit (Pianc Maritime navigation commission, 2014), should allow the ship to perform the required manoeuvres. While Pianc Maritime navigation commission (2014) rather arbitrarily suggests a manoeuvring margin of $5 \%$ of draft (with a minimum of $0.60 \mathrm{~m}$ ), it will be investigated whether this recommended value is sufficient for guaranteeing the controllability and manoeuvrability of ULCS over the complete trajectory. Possibly, the required manoeuvring margin will be variable along the trajectory; in straight stretches the manoeuvring margin could be less compared to bends. With respect to the latter, reference is made to (Eloot et al., 2007), where it was concluded that in confined river bends with steep banks, additional keel clearance is required to compensate for bank effects.

\subsection{WAVE CONDITIONS}

In order to relate the unsteady ship motions at sea to the acting wave climate, the significant wave height and the swell height $(\leq 0.1 \mathrm{~Hz})$ were derived from spectra measured at the directional wave buoy Bol van Heist (BVH, see Figure 7). 
Table 2. Wave parameters at Bol van Heist

\begin{tabular}{|c|c|c|}
\hline \multirow{2}{*}{ Ship } & $\begin{array}{c}\text { Significant } \\
\text { Wave } \\
\text { Height }\end{array}$ & $\begin{array}{c}\text { Significant } \\
\text { Swell } \\
\text { Height }\end{array}$ \\
\cline { 2 - 3 } & {$[\mathrm{m}]$} & {$[\mathrm{m}]$} \\
\hline ULCS 1 & 1.16 & 0.18 \\
\hline ULCS 2 & 0.30 & 0.02 \\
\hline ULCS 3 & 0.95 & 0.06 \\
\hline ULCS 4 & 0.89 & 0.07 \\
\hline ULCS 5 & 0.29 & 0.04 \\
\hline ULCS 6 & 1.20 & 0.06 \\
\hline ULCS 7 & 1.04 & 0.05 \\
\hline ULCS 8 & 0.57 & 0.04 \\
\hline ULCS 9 & 0.46 & 0.02 \\
\hline
\end{tabular}

Table 2 presents the wave parameters for the nine voyages, revealing important wave and swell heights for the vessel ULCS 1 and a large significant wave height for ULCS 6 .

\subsection{SHIP ENCOUNTERS}

Encounters with other shipping traffic revealed to have an important effect on vertical motion of the vessel. The presence of other shipping traffic was processed from AIS-information provided by the Scheldt Radar Chain (SRC). By means of a dedicated AIS-processing tool developed by FHR, the AIS data of the vessels that operated in the proximity of a reference vessel were identified and a table with (significant) ship meetings was generated. When presenting the squat motions of the vessels (see §5.2), some examples of ship encounters will be presented.

\subsection{SHIP SPEED}

In Figure 12 the speed over ground for the nine voyages is presented. An important variation in ship speed can be observed for different vessels. Also at some locations an important decrease of the ship speed can be noticed. The most striking example is the passage at Vlissingen $(\mathrm{s}=-65 \mathrm{~km})$, where the speed is reduced in order to facilitate the pilots to (dis)embark. Also at position $-17 \mathrm{~km}$ a drop in ship speed can be observed for all vessels. This location corresponds to the port of Walsoorden. The speed reduction at Walsoorden is applied in order to minimize the ship waves hindering the inland vessels moored in the port and the operations in a small drydock for ship repair. On the river Scheldt, for ULCS, it is required frequently to reduce speed to mitigate the interaction effects on inland barges.

From a hydrodynamic point of view, the speed through water is determining (see Figure 13). The speed through water is the relative speed between the vessel and the current. For most outbound voyages the river trajectory corresponded to flood currents. In this situation the sailing direction of the vessel is opposite to the current, leading to a higher speed through water than speed over ground. One can note that on the river trajectory the large speed over ground of the vessel ULCS 5 was strongly related to the ebb current this vessel was operating in. Looking to the speed through water the differences between the different vessels on the Western Scheldt are smaller than when the speed over ground was compared.

On the sea trajectory the largest ship speeds (up to $18 \mathrm{kn}$ ) were applied by the vessel ULCS 8 .

\subsection{RATE OF TURN}

In Figure 14 the rate of turn of the nine vessels is presented. Note that the one vessel following an inbound trajectory (ULCS 9) shows opposite values $(\mathrm{s}<-5 \mathrm{~km}$ ).

On the sea trajectory, in general, smaller yawing rates can be observed, except for the vessels using the Northern pilot station Steenbank (ULCS 5 and ULCS 9). Especially for the outbound ULCS 5 the bending manoeuvre at West Rond $(\mathrm{s}=-107 \mathrm{~km})$ did correspond to a high rate of turn (30 deg/min).

On the Western Scheldt the rate of turn reaches several peaks corresponding to the bends of the river. The most important rate of turn can be observed at $\mathrm{s}=-4 \mathrm{~km}$ (Bath) and $\mathrm{s}=-24 \mathrm{~km}$ (Hansweert) and were applied by the vessels ULCS 4 and ULCS 8 (approximately $28 \mathrm{deg} / \mathrm{min}$ ).

When comparing the rate of turn of the vessels (Figure 14) with the speeds of the vessels (Figure 13) a close relation between ship speed and rate of turn can be observed as the drifting and yawing motion of a vessel results in a decrease of the speed.

\section{VERTICAL SHIP MOTIONS}

In this chapter a first observation of the vertical motions will be presented. In order to separate the motions from different sources, the motions will be presented for the longitudinal (heave and pitch) and lateral (roll) sinkage and for the steady and unsteady motions separately.

\subsection{STEADY LONGITUDINAL SINKAGE}

The steady longitudinal sinkage is defined as the maximum sinkage at bow or stern resulting from the combined effect of the steady heave and steady pitch motions. The processing of this parameter depends on the ADX-measurement, the Octans-measurement and the tide reproduction. The results are only available in case both $\mathrm{ADX}$ and Octans were operational and provided accurate measuring results. The results of the steady longitudinal motions are presented in Figure 16.

The steady longitudinal sinkage can be considered to be mainly related to the squat of the vessel and the effect of the varying water density. For ship squat the main influencing parameters are the ship's speed (see Figure 13) and the under keel clearance (see Figure 11). Focussing on the motions on the sea trajectory, the relation between the steady longitudinal sinkage and the ship's speed is indeed noticeable. For example the vessel with the lowest ship speed (ULCS 9) did experience the smallest sinkages 
while the vessel applying the highest ship speeds (ULCS 8) did experience the largest sinkages reaching more than $1.6 \mathrm{~m}$. On the other hand the squat at the midship's position of vessel ULCS 6 was very limited, despites the important speed of more than $16 \mathrm{kn}$. The moderate squat motion for ULCS 6 is probably related to the small draft of this vessel and the corresponding large under keel clearances. Also when studying the longitudinal sinkage of a vessel on the Scheldt trajectory, the influence of under keel clearance on ship squat is clearly demonstrated.

The longitudinal sinkage is resulting from both heave and pitch motions. Full ship types, as studied in (Verwilligen et al., 2018b), will experience a bow down trim resulting in maximum squat occurring at the bow at all time. The present measurements of steady pitch on ULCS (see Figure 15) reveal that for the more slender container vessels the trim due to squat is less straight forward. For example focussing on the sea trajectory it can be observed that different ships experience an opposite trim. For most of the container vessels a bow down motion can be observed. However, for two of the vessels (ULCS 5 and ULCS 6), the trim resulting from squat was opposite (bow up) and for two of the vessels (ULCS 1 and ULCS 7) the trim on the sea trajectory was negligible. On the river trajectory $(\mathrm{s}>-65 \mathrm{~km})$ for most of the vessels the trim was changing between bow down and bow up. Comparing the results of the trim to the UKC (see Figure 11) reveals that the squat trim of the individual vessels tended to the bow in deep water and to the stern in more shallow water. This observations correspond to the results of squat measurements on scaled ULCS performed in the Towing Tank for Confined Water (Eloot et al., 2008). In the same reference, the trim motion is related to the draft of the vessel, stating that deep-drafted ULCS will squat more to the bow than the ballasted ULCS. From the full-scale measurements on the sea trajectory $(\mathrm{s}<-65 \mathrm{~km})$, this statement is confirmed for (most of the) the vessels with LOA $366 \mathrm{~m}$, showing bow up trim for the vessels with a draft of $11.3 \mathrm{~m}$ (ULCS 6) and bow down trim for most $366 \mathrm{~m}$ vessels with draft more than $13.0 \mathrm{~m}$ (ULCS 2, ULCS 3, ULCS 4 and ULCS 8). The bow up trim of ULCS 6 may also be related to the static trim of the vessel. ULCS 6 was trimmed by the stern with $0.4 \mathrm{~m}$. On the other hand ULCS 1, drafted $14.15 \mathrm{~m}$ presents negligible trim on the sea trajectory. Of course the draft of the vessel and the tidal conditions also influence the keel clearance. In $\S 4.2$ it was noticed that vessel ULCS 1 was sailing at the end of its tidal window corresponding to relatively low under keel clearances on the sea trajectory (see Figure 11). The small under keel clearances for vessel ULCS 1 may explain the trim to be less bow down than expected based on the draft of the vessel.

For the longer ULCS $\left(\mathrm{LOA}_{\mathrm{OA}}>397 \mathrm{~m}\right)$ the relation between the ship's draft and the trim at the sea trajectory motions is less consistent, showing negligible trim for ULCS 7 with draft $15.1 \mathrm{~m}$ and (mainly) bow down trim for ULCS 9 with draft $10.1 \mathrm{~m}$.

From the steady longitudinal sinkage, also the density effect on the ship's draft is observed. The vessel's speed is reduced at Vlissingen $(\mathrm{s}=-65 \mathrm{~km})$ in order to facilitate the pilot change (see Figure 13). At this low speed the sinkage of the vessel due to squat becomes very small so that for outbound vessels, the main effect on the steady heave motion corresponds to the decrease of the ship's draft and change in trim due to the increase in water density (see Table 1).

The negative sinkages (upwards) at low speeds for outbound vessels (see Figure 16) correspond to the hydrostatic effect of the water density on the ship's draft.

\subsection{UNSTEADY LONGITUDINAL SINKAGE}

In Figure 17 the unsteady longitudinal sinkage is presented. On the sea trajectory only two vessels (ULCS 1 and ULCS 6) experienced a significant motion due to waves. This relation between sea state and unsteady motions is illustrated by comparing the motions of the vessel to the significant wave height and the swell component in the coastal wave spectra (see $\S 4.3$ ).

Furthermore, also for other vessels isolated unsteady longitudinal motions could be observed both on river and sea trajectory. When comparing these motions to the results of the AIS-processing (see §4.4) these motions could be related to ship encounters. In this paper two examples are presented for which the conditions and added sinkages are summarized in Table 3.

A first example concerns the meeting of the vessel ULCS 4 with a $319 \mathrm{~m}$ container vessel in the Wielingen (sea trajectory). The vessels were meeting at a relatively large lateral distance but at rather important ship speed's over ground of 14.6 and $21.0 \mathrm{kn}$ respectively. Taking into account the current, the meeting vessel was sailing at a speed through water of approximately $19.5 \mathrm{kn}$ leading to an added sinkage of $0.4 \mathrm{~m}$. A second example concerns the vessel ULCS 5 being overtaken by a $205 \mathrm{~m}$ ConRo vessel, leading to an increased sinkage of $0.3 \mathrm{~m}$ on the ULCS. In this case, the overtaking vessel applied a speed through water of approximately $18.5 \mathrm{kn}$ which was $6.2 \mathrm{kn}$ more than the vessel ULCS 5. 
Table 3. Conditions of two important ship encounters based on AIS-analysis

\begin{tabular}{|c|c|c|c|}
\hline Date & {$[-]$} & $15 / 12 / 2017$ & $27 / 01 / 2018$ \\
\hline Time UTC & {$[-]$} & $9: 07: 35$ & $1: 45: 05$ \\
\hline Own ship name & {$[-]$} & ULCS 4 & ULCS 5 \\
\hline Own ship SOG & {$[\mathrm{kn}]$} & 14.6 & 13.8 \\
\hline Own ship UKC & {$[\%]$} & $45 \%$ & $28 \%$ \\
\hline $\begin{array}{c}\text { Meeting ship } \\
\text { type }\end{array}$ & {$[-]$} & $\begin{array}{c}\text { Container } \\
\text { vessel }\end{array}$ & ConRo vessel \\
\hline $\begin{array}{c}\text { Meeting ship } \\
\text { Length }\end{array}$ & {$[\mathrm{m}]$} & 319 & 205 \\
\hline $\begin{array}{c}\text { Meeting ship } \\
\text { Beam }\end{array}$ & {$[\mathrm{m}]$} & 40 & 26 \\
\hline $\begin{array}{c}\text { Meeting ship } \\
\text { Draft }\end{array}$ & {$[\mathrm{m}]$} & 11.1 & 8.3 \\
\hline $\begin{array}{c}\text { Meeting ship } \\
\text { SOG }\end{array}$ & {$[\mathrm{kn}]$} & 21.0 & 20.0 \\
\hline $\begin{array}{c}\text { Minimal Dis- } \\
\text { tance }\end{array}$ & {$[\mathrm{m}]$} & 227 & 165 \\
\hline $\begin{array}{c}\text { Relative speed } \\
\text { between ships }\end{array}$ & {$[\mathrm{kn}]$} & 35.5 & -6.2 \\
\hline $\begin{array}{c}\text { Extra sinkage } \\
{[\mathrm{m}]}\end{array}$ & 0.4 & 0.3 \\
\hline
\end{tabular}

\subsection{STEADY LATERAL SINKAGE}

In Figure 18 the steady lateral sinkage is presented as the vertical downward motion of the ship bilges related to the steady roll motion of the vessels. Large steady roll motions can be observed in the bends at Bath $(-4 \mathrm{~km})$, Hansweert $(-24 \mathrm{~km})$ and Borssele $(-55 \mathrm{~km})$. The most important steady roll motions are observed on the vessels ULCS 8 and ULCS 3 and to a lesser extent on ULCS 1. Those vessels were also those with the smallest metacentric height $\left(\mathrm{GM}^{\prime}<3.2 \mathrm{~m}\right)$. Compared to the other vessels the stability of these vessels could be considered low.

A strong relation between rate of turn (see Figure 14), ship speed (see Figure 13) and steady roll motion can be observed. Furthermore also at straight trajectories a small steady roll angle remains that could not be related to the yawing motion of the vessel. Further analysis will investigate the effect of wind and other parameters (current, banks) on the rolling motion of the vessel.

\subsection{UNSTEADY LATERAL SINKAGE}

Figure 19 presents the sinkage related to the unsteady roll motion of the vessels. Although wave action is absent on the river trajectory, the unsteady roll motions seem to be significantly larger on the river than at sea, so that the main reason for unsteady roll motion is not related to the ship responses to waves but to another disturbance of the vessel. From the results of the camera monitoring (see $\$ 2.2$ (c)), it could be analysed that the unsteady roll motion was strongly correlated to deviations in rudder angle. The rolling moment induced by the lifting force on the rudder seems to have an important impact on the roll motions of the vessels on the river Scheldt. Also on the sea trajectory some important roll motions, probably related to rudder action, can be observed.

From the measurement results it can be deduced that the main effects influencing the roll motions are the roll moments induced by the centrifugal force and by rudder forces . In a steady bend, the centrifugal forces are acting in the centre of gravity of the vessel to a direction outwards of the bend. As also the rudder induced force is acting outwards, a hydrodynamic reaction force is required so as to obtain a force equilibrium. For container vessels the centre of gravity is at a relatively high position (at least higher than the vertical position of the application point of the hydrodynamic reaction force which is approximately at half draft) so that the centrifugal force makes the vessel heel to the outer bend. However, in case of a rudder command (i.e. a sudden change of the rudder angle), initially the rudder force and the lateral inertia force will generate a heeling moment which has an opposite sign compared to the eventual steady state. This effect is particularly important when the rate of turn of the vessel needs to be reduced, and counter rudder is given. At that moment the roll moment induced by the rudder action acts in the same direction as the roll moment induced by the centrifugal force. As a consequence the largest roll motions occur when the rate of turn of a vessel is reduced drastically due to a large counter rudder. However, also large unsteady motions occur on straight stretches when consecutive (short) applications of large rudder angles are applied and resonate with the roll dynamics of the vessel. An example of this effect corresponds to the significant unsteady roll motion of ULCS 2 at $\mathrm{s}=-101 \mathrm{~km}$.

In $\S 5.3$ it was noticed that the steady roll motion showed some relation with the stability of the vessel. Also for the unsteady roll motions the vessels ULCS 8 and ULCS 3 with low metacentric height did experience large unsteady motions, but the largest unsteady roll motions occurred on the vessel ULCS $4(\mathrm{GM}=4.84 \mathrm{~m})$. It can be concluded that the stability of the vessel is not the only parameter influencing the unsteady rolling motion. Other parameters involved are most likely related to the rudder and propeller equipment and the application of rudder angles by the helmsman.

The impact of waves of the (unsteady) roll motion could not be deduced from the measurement results.

\section{CONCLUSIONS}

From September 2017 to July 2018 the Flemish Pilotage executed nine ship measurements on container ships to and from Antwerp. The measurement results were processed by Flanders Hydraulics Research and Ghent University providing $6 \mathrm{DoF}$ motions of the vessels. 
Furthermore environmental data regarding tide, currents, waves, bathymetry and AIS were processed in order to assess the influence of environmental conditions on the vertical ship motions.

The vertical ship motions are presented separately for the longitudinal and lateral sinkages and for steady and unsteady motions.

The longitudinal steady sinkages correspond mainly to squat, and to a lesser extent to varying water density along the trajectory. The influence of ship speed and under keel clearance on ship squat is demonstrated. Also the relation of the ship's loading condition and keel clearance on the trim direction is discussed and compared to previous observations based on towing tank results.

The unsteady longitudinal sinkages are related to sea keeping and to added squat due to ship encounters.

The major phenomena driving the roll motions on the river trajectory concern heeling in bends (steady) and the dynamic response on the rolling moment due to rudder actions (unsteady). Especially the steady roll motions show a strong relation with the initial stability of the vessels. For the unsteady roll motions also other parameters (e.g. rudder design) seem to be important.

The paper presents the first results of an extensive data processing. The data opens opportunities for an in depth analysis for the ship behaviour in shallow and confined water, not only related to vertical ship motions but also to the manoeuvring behaviour of the vessel. At present future work is planned in the field of squat modelling and on the roll behaviour of ULCS. In a next step Flanders Hydraulics Research and Ghent University like to apply the measurement results to validate the mathematical manoeuvring models derived from the towing tank.

\section{ACKNOWLEDGEMENTS}

The work presented in this paper is the result of a fruitful collaboration between several partners involved. The authors want to acknowledge in particular the Common Nautical Authority and the Flemish Pilotage DAB Loodswezen.

For reproducing the environmental conditions a lot of data from different sources and databases were provided by:

the Flemish Hydrography, Dutch ministry of infrastructure and water management (Rijkswaterstaat) and the Scheldt Radar Chain.

This research could not be executed without the financial support of the Common Nautical Authority in which the Flemish Shipping Assistance Division (BE) and the Dutch ministry of infrastructure and water management, Rijkswaterstaat (NL) are represented.

\section{REFERENCES}

Eloot, K., Verwilligen, J., Vantorre, M., 2008. An Overview of Squat Measurements for Container Ships in Restricted Water, in: International Conference on Safety and Operations in Canals and Waterways SOCW 2008, 15-16 September. Glasgow, UK, pp. 106-116.
Eloot, K., Verwilligen, J., Vantorre, M., 2007. A methodology for evaluating the controllability of a ship navigating in a restricted channel, in: Archives of Civil and Mechanical Engineering: Quarterly. Oficyna

Wydawnicza Politechniki Wroclawskiej, pp. 91-104. https://doi.org/10.1016/S1644-9665(12)60016-8

Geerts, S., Verwilligen, J., Eloot, K., Mostaert, F., 2016. Ontwikkeling meetapparatuur aan boord van schepen: Deelrapport 6 - Gebruikershandleiding camerasysteem MIM_FHR_v2. Antwerp.

Pianc - Maritime navigation commission, 2014. Harbour approach channels design guidelines - Report $n^{\circ} 121$ 2014. Brussels, Belgium.

van Buuren, W., 2005. Beschrijving van de NMS type ADX. November 2005.

Vantorre, M., Candries, M., Verwilligen, J., 2014. Optimisation of Tidal Windows for Deep-Drafted Vessels by Means of a Probabilistic Approach Policy, in: PIANC World Congress. San Francisco, USA.

Verwilligen, J., Mansuy, M., Vantorre, M., Eloot, K., 2018a. Full-scale measurements to assess squat and vertical motions in exposed shallow water, in: Proceedings of the 34th PIANC World Congress 2018 in Panama City, Panama. PIANC.

Verwilligen, J., Mansuy, M., Vantorre, M., Eloot, K., 2018b. Squat formula for cape-size bulk carriers based on towing tank results and full-scale measurements, in: MARSIM 2018, Halifax, Canada, 12 - 16 August 2018. IMSF.

\section{AUTHORS BIOGRAPHY}

Jeroen Verwilligen holds the current position of senior expert in nautical research at Flanders Hydraulics Research. He is experienced with simulation studies, nautical accessibility studies and full scale measurements. $\mathrm{He}$ is member of the PIANC MarCom WG 171 on Ship Handling Simulation Dedicated to Channel and Harbour Design.

Katrien Eloot holds the current position of senior expert in nautical research at Flanders Hydraulics Research. Through her $\mathrm{PhD}$ on selection, experimental determination and evaluation of mathematical manoeuvring models she is active in the field of math model development for ship behaviour in shallow and confined water and the execution of simulation studies for clients coping with issues on shallow water manoeuvring. She is member of PIANC InCom WG 141 on Design Guidelines for Inland Waterway Dimensions which will disseminate the report results through 2019.

Marc Mansuy holds the current position of research staff at Gent University. He has been working on different 
projects related to maneuvering in shallow and confined water at Flanders Hydraulic Research and Ghent University.

He has some expertise in waterway accessibility, ship maneuverability on real time and fast time simulators and full scale measurements.

Marc Vantorre, naval architect, is emeritus professor of marine hydrodynamics and former head of the Maritime Technology Division at Ghent University, Belgium. His research focuses on ship behaviour in shallow and confined waters, mainly in close co-operation with Flanders Hydraulics Research in Antwerp. He is former member of PIANC Working Groups and of the ITTC Manoeuvring Committee. 


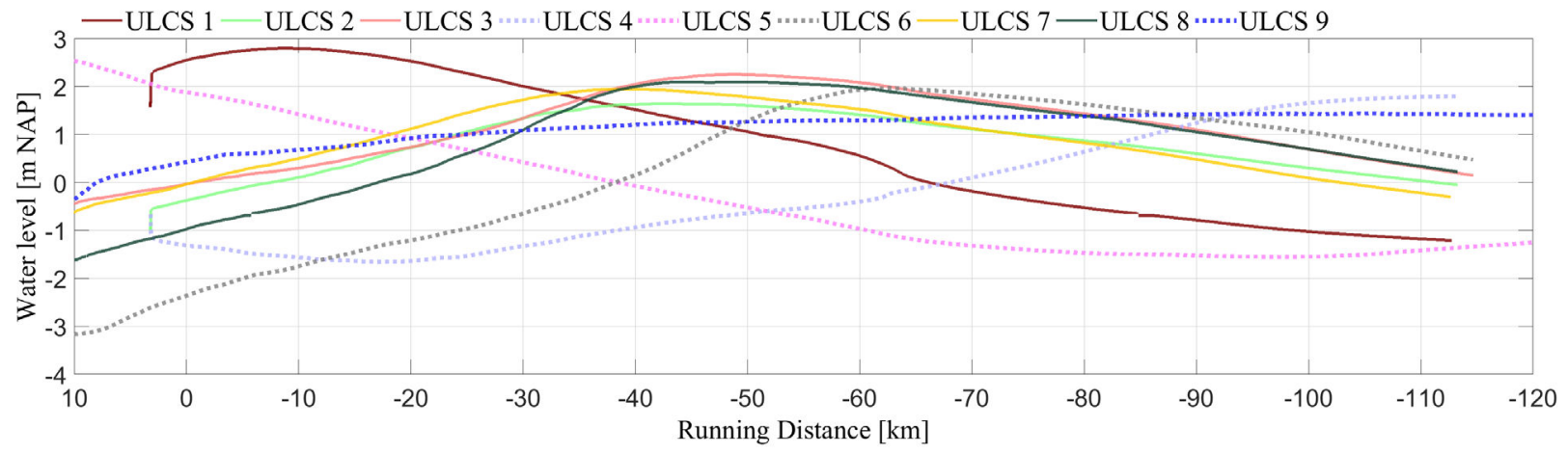

Figure 8. Tide evolution during nine voyages

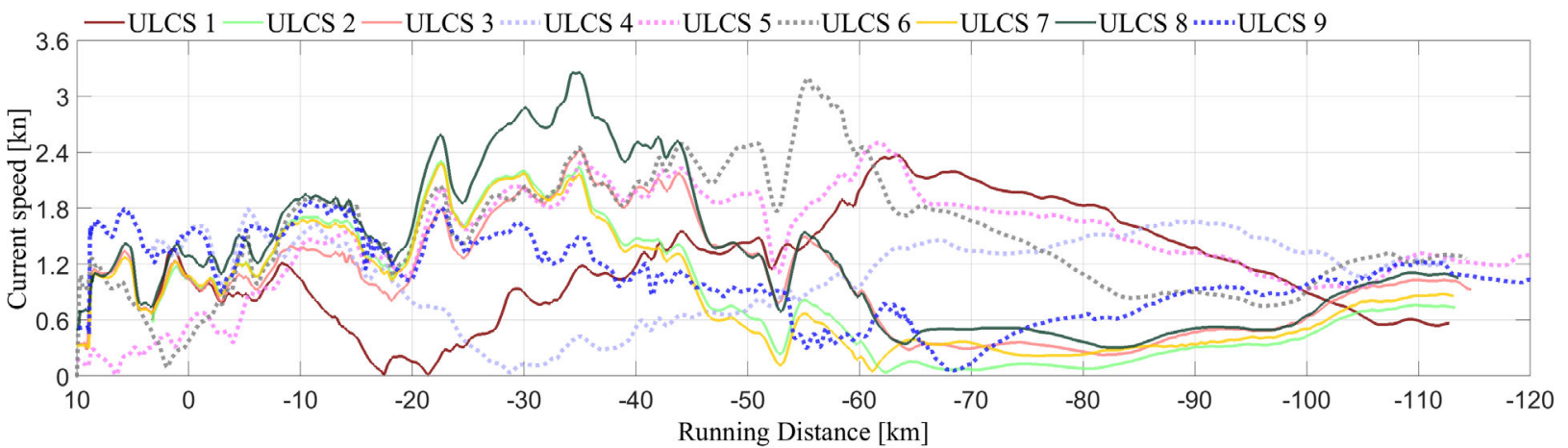

Figure 9. Current magnitude during nine voyages

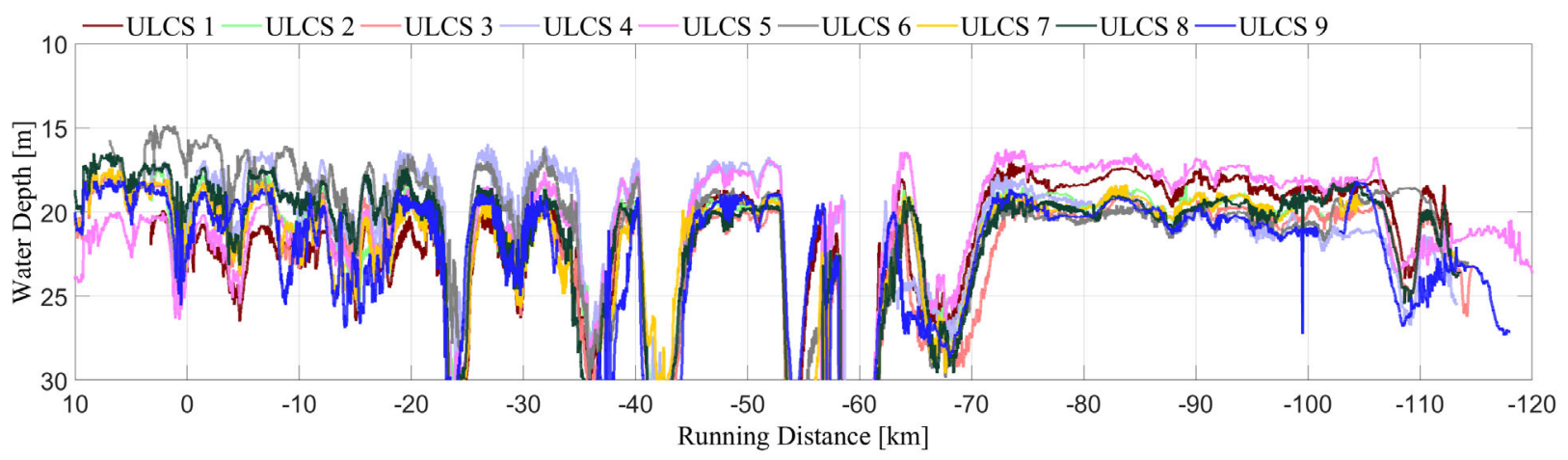

Figure 10. Water depth during nine voyages

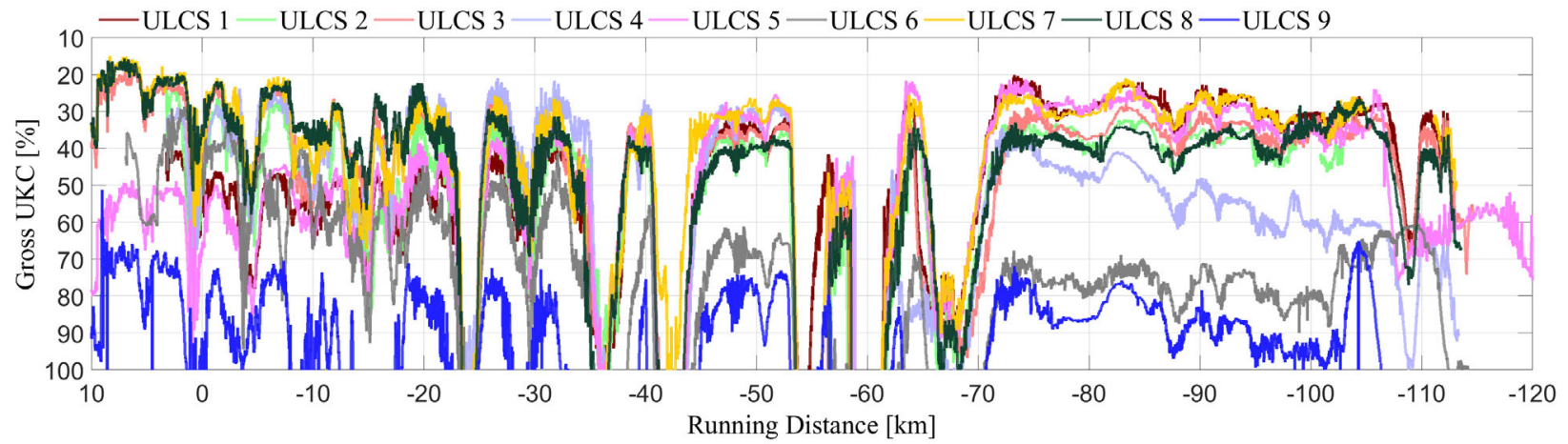

Figure 11. Gross UKC during nine voyages 


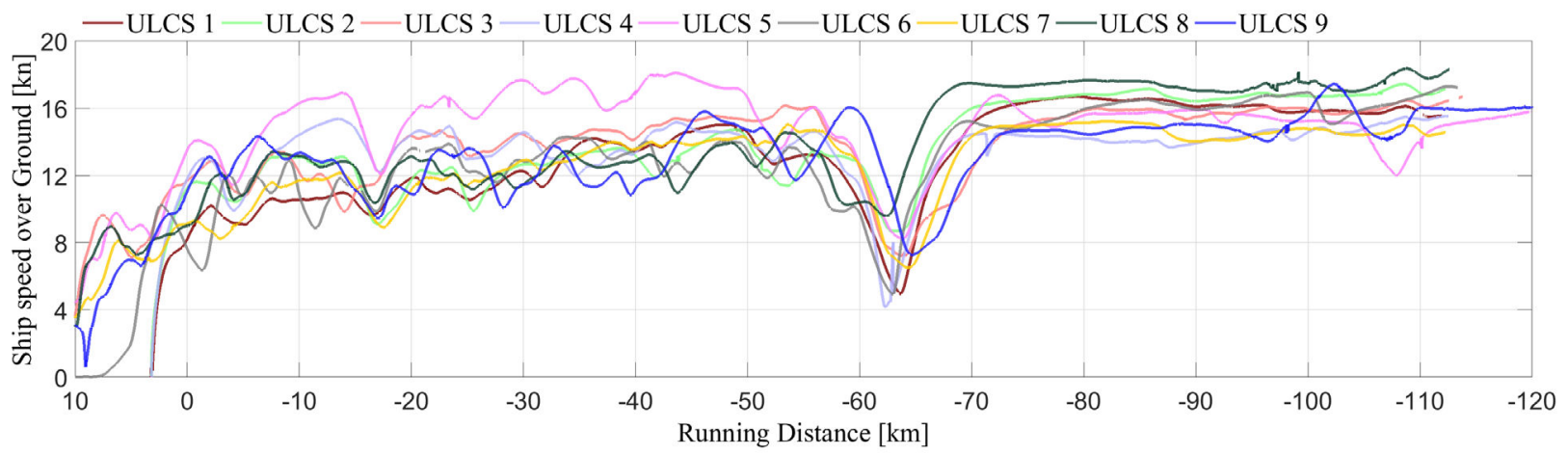

Figure 12. Ship speed over ground during nine voyages

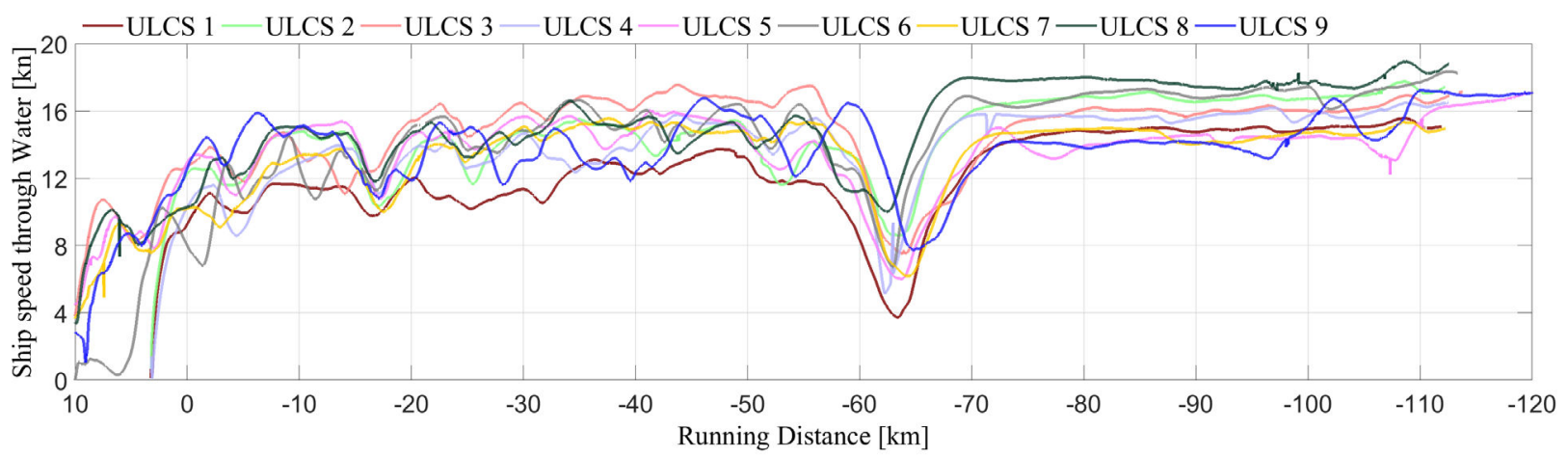

Figure 13. Ship speed through water during nine voyages

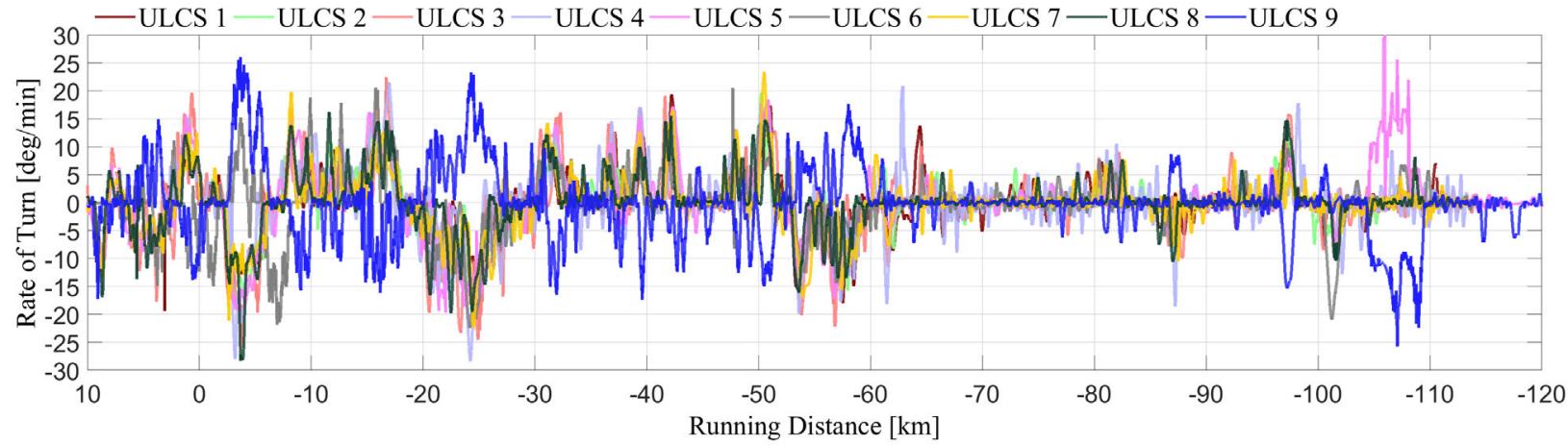

Figure 14. Rate of Turn during nine voyages

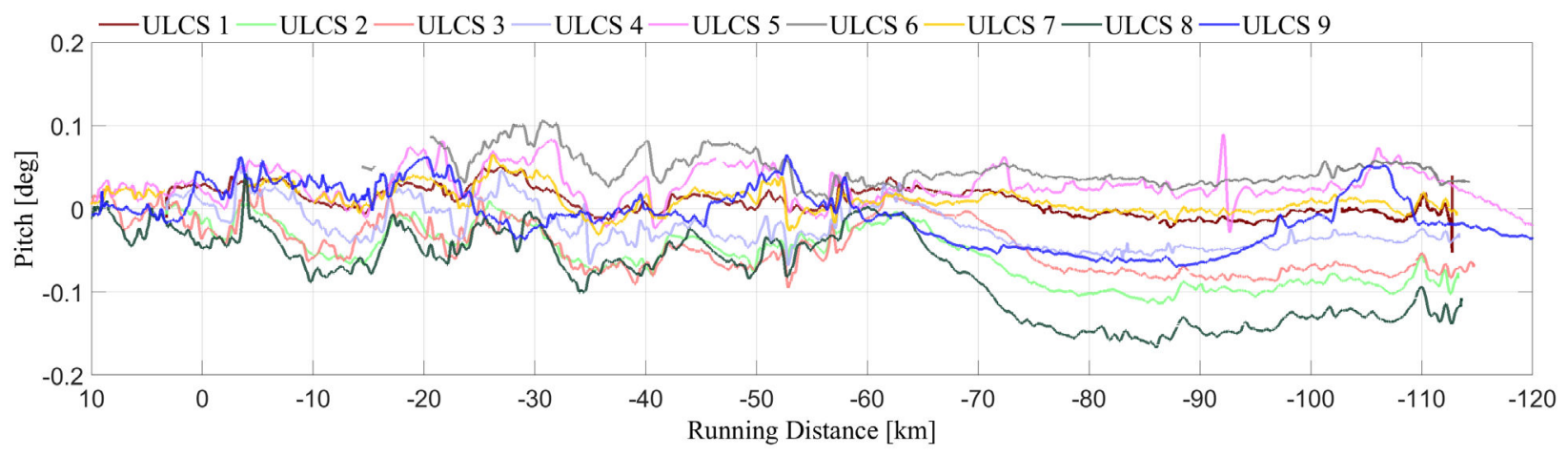

Figure 15. Steady pitch motion (trim) during nine voyages 


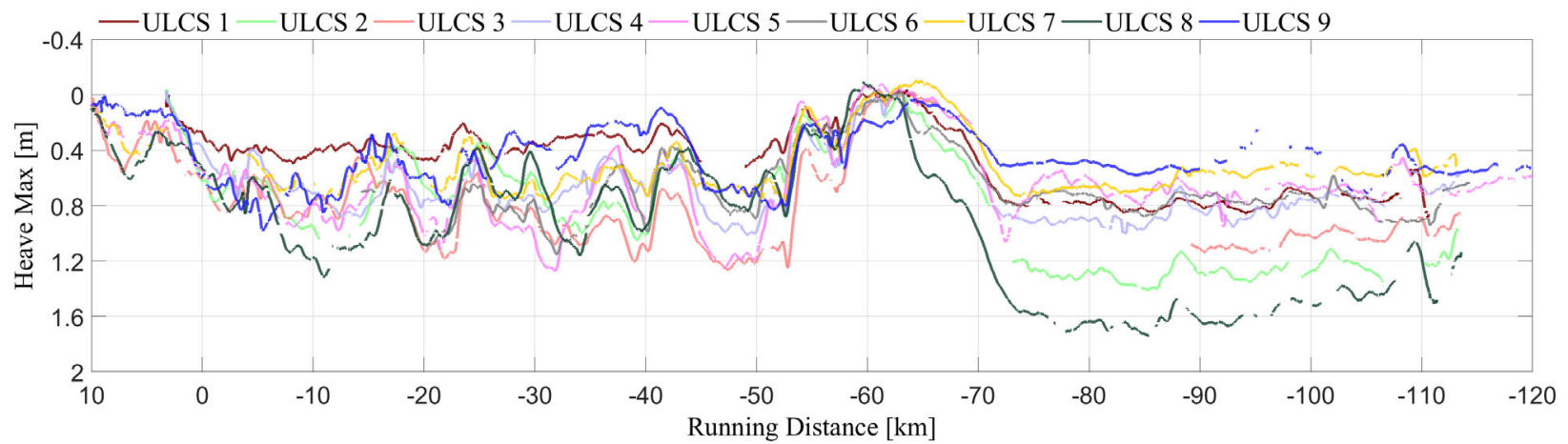

Figure 16. Steady longitudinal sinkage during nine voyages

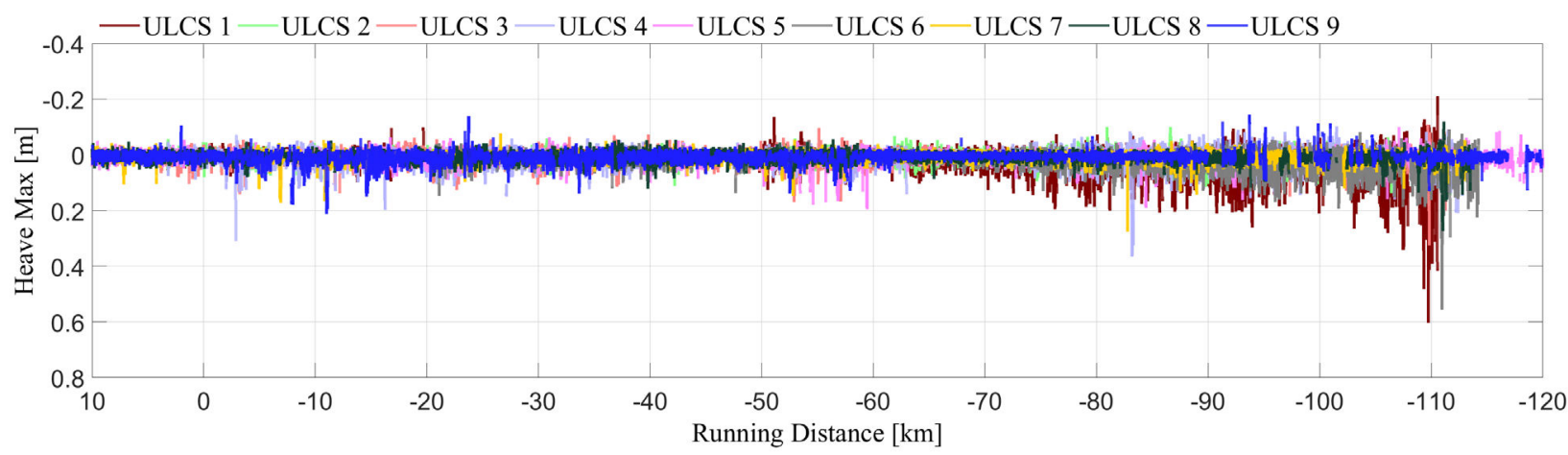

Figure 17. Unsteady longitudinal sinkage during nine voyages

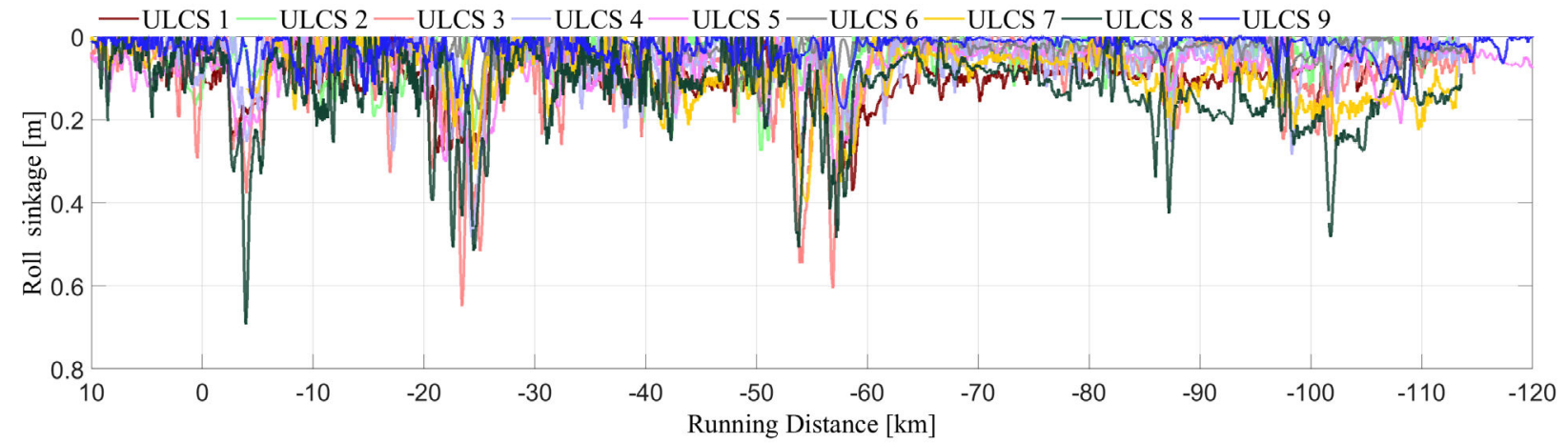

Figure 18. Steady lateral sinkage (heel) during nine voyages

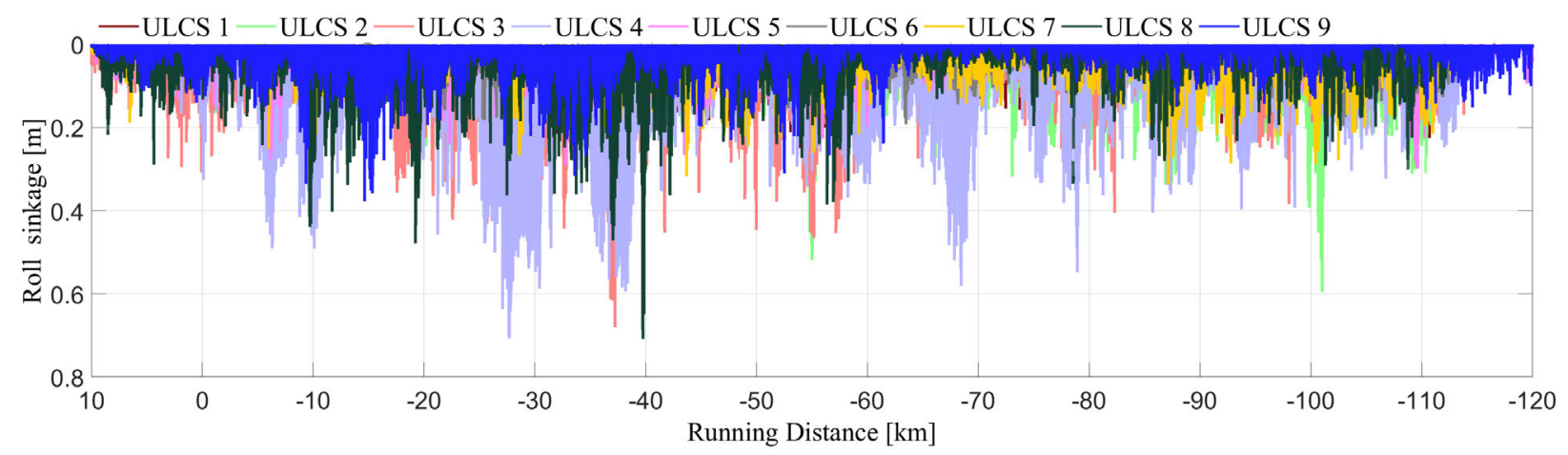

Figure 19. Unsteady lateral sinkage during nine voyages 